\title{
PISO MISTO DE PEQUENA ALTURA: COMPONENTES E PROCESSO CONSTRUTIVO
}

\section{COMPOSITE SLIM FLOOR: ELEMENTS AND CONSTRUCTION PROCESS}

\author{
Raimundo Fagner de Freitas Kochem ${ }^{1}$ \\ Universidade Federal de São Carlos, São Carlos, SP, Brasil, raimundokochem@gmail.com \\ Silvana De Nardin 2 \\ Universidade Federal de São Carlos, São Carlos, SP, Brasil, snardin@ufscar.br
}

\section{Resumo}

A procura por sistemas construtivos mais eficientes vem crescendo gradualmente nos últimos anos no Brasil. Neste cenário está inserido o sistema misto de aço e concreto que apresenta grandes vantagens tanto estruturais como construtivas. $\mathrm{O}$ piso misto de pequena altura trata-se da associação entre viga mista e laje mista, cuja principal característica é o embutimento da viga na laje; tal embutimento proporciona redução da altura total do sistema laje-viga aumentando o pé-direito do pavimento. Por ser um sistema em que grande parte dos elementos é industrializado, o piso misto de pequena altura permite diversas combinações entre vigas e lajes, sempre mantendo sua principal característica que é o embutimento total ou parcial da laje na viga. Assim, tomando o piso misto de pequena altura como objeto de estudo, o presente artigo apresenta as principais características desse sistema, descreve os principais componentes, dando destaque aos componentes pré-fabricados, às técnicas inerentes ao processo construtivo, incluindo equipamentos necessários à execução e detalhes construtivos. Isto é feito para quatro configurações de piso misto de pequena altura: perfil Deltabeam ${ }^{\circledR}$ e laje mista; perfil Deltabeam ${ }^{\circledR}$ e laje pré-fabricada de concreto, perfil I assimétrico de aço associado a laje mista e perfil I assimétrico e laje pré-fabricada de concreto.

Palavras-chave: Estrutura mista de aço e concreto. Piso misto de pequena altura. Sistema construtivo industrializado. Processo de construção.

\begin{abstract}
The demand for more efficient construction systems has been growing gradually in recent years in Brazil. In this scenario is inserted the composite system of steel and concrete that presents excellent advantages both structural and constructive. The slim composite floor is the association between the composite beam and the composite slab, whose main characteristic is the embedment of the beam in the slab; such as inlay, that provides a reduction in the total height of the slab-beam system increasing the height of the pavement. Because it is a system in which a large part of the elements are industrialized, the slim composite floor allows several combinations between beams and slabs, always maintaining its main characteristic which is the whole or partial whole of the slab in the beam. Thus, taking the slim composite floor as the object of study, this article presents the main characteristics of this system, describing the main components, highlighting the prefabricated components, the techniques inherent to the construction process, including the equipment necessary for the execution and constructive details. The description is developed for four configurations of the slim composite floor: Deltabeam profile and composite slab; Deltabeam profile and prefabricated concrete slab; asymmetrical steel I profile associated with composite slab and asymmetrical profile I, and precast concrete slab.
\end{abstract}

Keywords: Composite structures. Composite slim floor. Industrialized building system. Construction process.

\section{How to cite this article:}

KOCHEM, Raimundo Fagner Freitas; DE NARDIN, Silvana. Piso misto de pequena altura: componentes e processo construtivo. PARC Pesquisa em Arquitetura e Construção, Campinas, SP, v. 9, n. 3, p. 223-233, set. 2018. ISSN 1980-6809. Disponível em:

<https://periodicos.sbu.unicamp.br/ojs/index.php/parc/article/view/8650817>. Acesso em: 16 set. 2018.

doi:https://doi.org/10.20396/parc.v9i3.8650817 


\section{Introdução}

A busca por construções mais eficientes tem feito com que a procura e utilização dos sistemas industrializados crescesse gradualmente nas últimas décadas no Brasil. Dentro deste contexto está inserido o sistema misto de aço e concreto, cujo as principais características são a velocidade de execução, grande controle dimensional e de qualidade dos componentes industrializados, fácil instalação e manutenção dos sistemas prediais, menor geração de resíduos, redução na quantidade de fôrmas, grande capacidade resistente e rigidez.

A Federação Internacional do Concreto (FIB, 2002) salienta que a pré-fabricação traz a vantagem da rápida execução aliada a elementos estruturais com elevada qualidade e precisão dimensional. Assim, a combinação entre elementos do sistema misto com do pré-fabricado pode resultar em uma estrutura com maior qualidade, executada com maior rapidez e economia, com geração de menor volume de resíduos de construção.

Os elementos mistos de aço e concreto são caracterizados pela presença do aço, sob a forma de perfil, trabalhando de maneira conjunta com o concreto simples ou armado para resistir às ações. Dentre os elementos estruturais que o compõem têm-se as vigas, os pilares, as lajes e as ligações. O piso misto é a associação entre a viga mista e a laje mista de modo que, se a laje é posicionada sobre a viga tem-se o piso misto convencional (Figura 1a) e quando a laje é apoiada na mesa inferior da viga tem-se o piso misto de pequena altura (Figura 1b).

Figura 1 - Tipologias de pisos mistos de aço e concreto

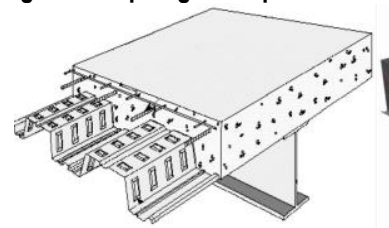

(a)

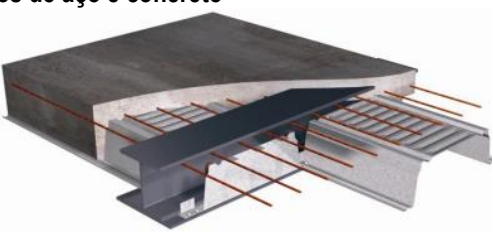

(b)

Fonte: (a) Adaptado de Sommer (2002); (b) Arcelormittal (2014).

A primeira configuração do piso misto de pequena altura que se tem conhecimento é datada de 1790 e foi denominada jack-arch (Figura 2a). O sistema consistia de arcos de blocos cerâmicos apoiados na mesa inferior de vigas de ferro fundido. No início do século XIX surge outra seção do piso misto de pequena altura, o filler joist (Figura 2b), formado por vigas de aço envoltas por concreto (BAILEY, 1999). Devido ao sucesso do piso misto de pequena altura nos países nórdicos, as associações British Steel (BS) e Steel Construction Institute (SCI) desenvolveram, em conjunto, estudos no para avaliar a capacidade resistente e as características deste sistema construtivo (JURADO, 2008).

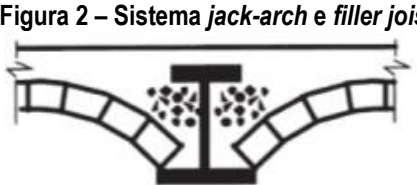

(a)

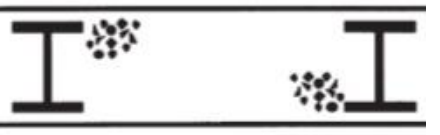

(b)
Fonte: Bailey (1999).

A principal característica do piso misto de pequena altura é o embutimento da viga na laje, o que resulta em redução da altura total do sistema laje-viga. Esta redução torna possível aumentar o número de pavimentos mantendo a altura total do edifício ou, em regiões com limitações de gabarito, pode ocorrer a redução da altura total da edificação sem a consequente redução do número de pavimentos. Porém, além da redução da altura do sistema laje-viga, o piso misto de pequena altura apresenta grande resistência ao fogo uma vez que as vigas são parcialmente revestidas pelo concreto da laje. Estudos mostraram que a resistência de um piso misto ao fogo é de aproximadamente 60 minutos sem a utilização de proteção adicional contra incêndio (MA; MAKELAINEN, 2000). $\mathrm{O}$ envolvimento parcial do perfil de aço pelo concreto também contribui para aumentar a resistência às instabilidades locais e globais do perfil de aço. Por ser um sistema em que grande parte dos componentes é industrializada, o piso misto de pequena altura possui grande versatilidade, o que permite diversas combinações entre a viga mista e a laje.

Dentre as combinações possíveis para o piso misto de pequena altura as que apresentam maiores vantagens são as compostas por perfil I assimétrico de aço e laje mista com fôrma de aço incorporada (Figura 3a), perfil I assimétrico de aço e laje pré-fabricada de concreto (Figura $3 b$ ), perfil Deltabeam ${ }^{\circledR}$ e laje mista (Figura 3c) e perfil Deltabeam ${ }^{\circledR}$ e laje pré-fabricada (Figura 3d).

Figura 3 - Exemplos de pisos mistos de pequena altura

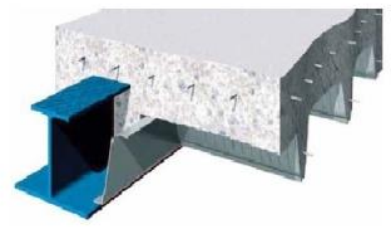

(a)

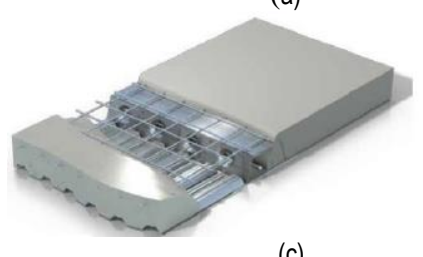

(c)

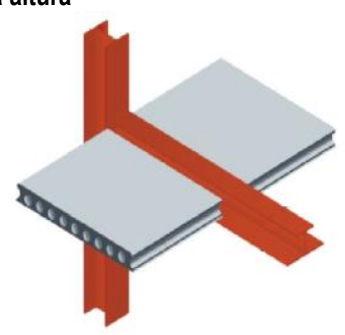

(b)

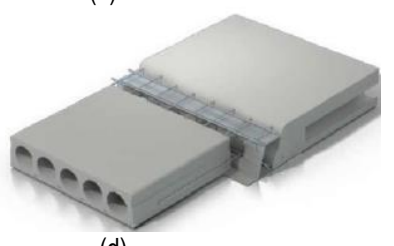

(d)
Fonte: (a) Tata Steel (2016); (b) Arcelormittal (2014); (c, d) Peikko Group (2014). 


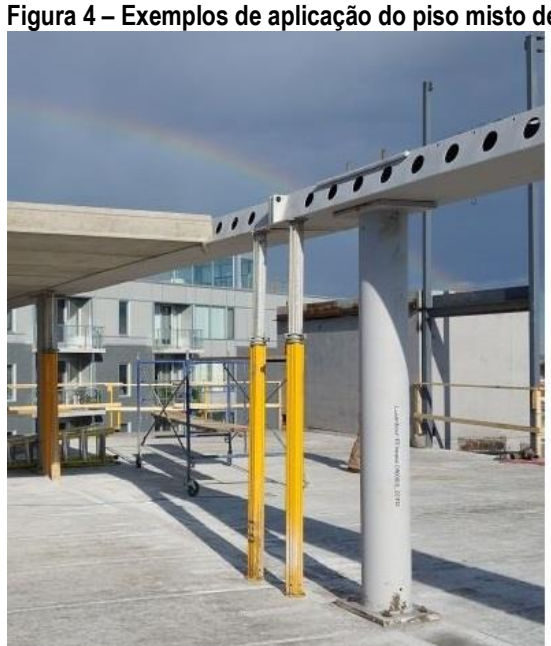

(a)

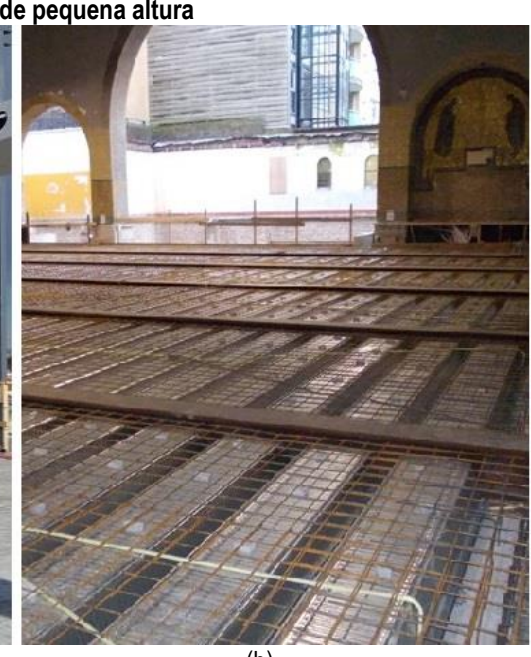

(b)

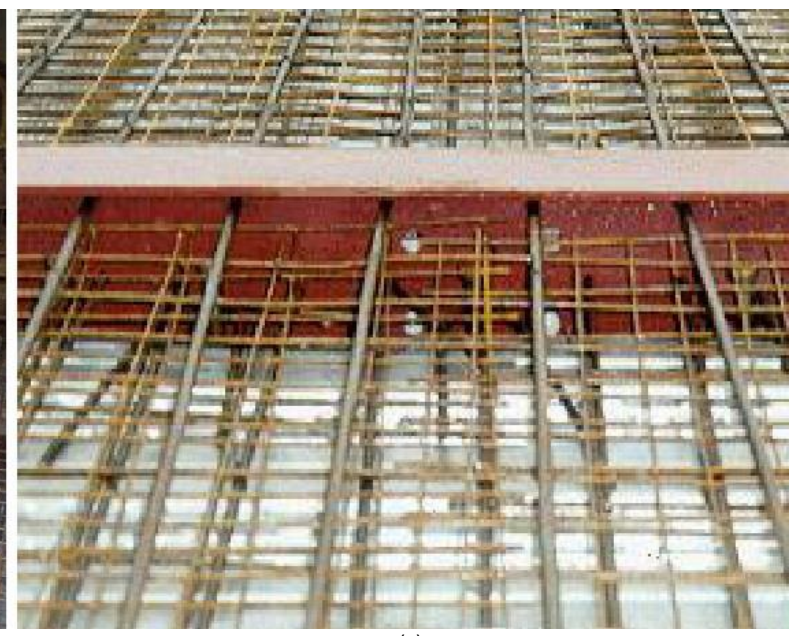

(c)

Fonte: (a) Peikko Group (2017); (b) Tata Steel (2017); (c) Queiroz et al. (1998)

Os sistemas citados apresentam boas características estruturais e construtivas pois a grande maioria dos componentes são industrializados, restando somente a montagem da estrutura, execução de capa de concreto moldado no local e execução de outros poucos serviços no canteiro de obras. Além disso, com a utilização de lajes pré-fabricadas a superfície final da laje tem um acabamento inicial muito bom, demandando pouco material e serviços para regularização de superfície antes do assentamento de piso.

Internacionalmente o piso misto de pequena altura é denominado slim floor e comercializado, em sua grande maioria, em sistemas patenteados. Sua utilização já é bem difundida, exemplo disso são os edifícios residenciais Luxenbourg II e III localizados em Quebec no Canadá (Figura 4a) constituído por vigas mistas com perfil Deltabem ${ }^{\circledR}$ de $250 \mathrm{~mm}$ de altura e laje alveolar e Chasse Church em Amsterdam na Holanda (Figura 4b) com piso composto de perfis I assimétricos e laje mista com forma de aço incorporada com $210 \mathrm{~mm}$ de altura. No Brasil, exemplo de aplicação é um edifício construído em Belo Horizonte - MG (Figura 4c) composto de vigas metálicas com altura de 200 a $250 \mathrm{~mm}$ e laje mista com forma de aço incorporada (QUEIROZ et al., 1998). Nesse sistema, o comportamento conjunto aço-concreto foi promovido pela passagem de barras de aço por furos feitos na alma dos perfis I assimétricos. Em algumas regiões também foram utilizados conectores de cisalhamento tipo pino com cabeça para esse mesmo fim.

Uma vez apresentado um contexto geral sobre os pisos mistos de pequena altura, com objetivo de contribuir com o conhecimento do processo construtivo do sistema em estudo, o presente artigo apresenta as principais características desse sistema, os principais componentes, dando destaque para os componentes pré-fabricados e as técnicas inerentes ao processo construtivo, incluindo os equipamentos necessários à sua execução.

\section{Componentes do piso misto de pequena altura}

Por ser um sistema em que predominam os componentes industrializados, o piso misto de pequena altura possui grande versatilidade, o que permite diversas combinações entre viga mista e laje. Entre os perfis disponíveis para compor o piso misto de pequena altura tem-se os perfis I assimétricos (Figura 5a), celular (Figura 5b), Deltabeam ${ }^{\circledR}$ (Figura 5c) e tubular retangular (Figura 5d). Dentre esses, nesse trabalho são abordados os perfis I assimétrico e o Deltabem ${ }^{\circledR}$.

Figura 5 - Perfis do piso misto de pequena altura

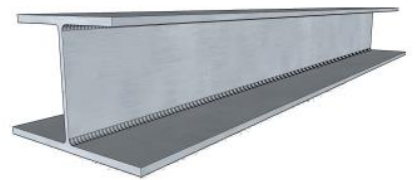

(a)

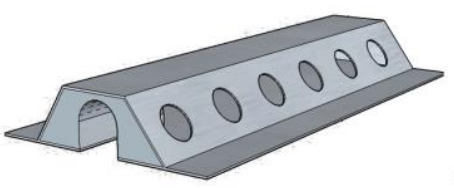

(c)

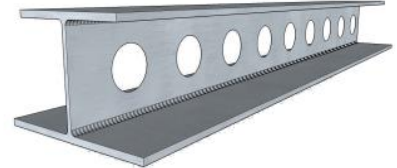

(b)

(d)

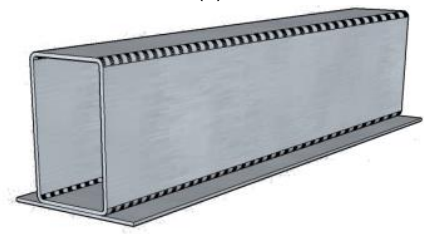

Fonte: Os autores.

Dentre os perfis I assimétricos merecem destaque os perfis patenteados como Slimflor Fabricated Beam (SFB), Asymmetric Slimflor Beam (ASB) e Integrated Floor Beam (IFB) sendo que uma das principais diferenças entre esses perfis I citados é o processo de fabricação. O perfil SFB é obtido a partir de um perfil I ou $\mathrm{H}$ simétrico ao qual é soldada uma chapa de aço em uma das mesas. 
Usualmente a chapa utilizada para aumentar a largura de suporte da laje tem $15 \mathrm{~mm}$ de espessura e ultrapassa a largura da mesa em $100 \mathrm{~mm}$ para permitir o apoio da fôrma de aço (Figura 6a). Essa é uma boa solução para países como o Brasil, que não tem tradição no uso de perfis assimétricos e, por isso, esse tipo de elemento estrutural não é facilmente encontrando no mercado nacional. Já o perfil IFB é obtido a partir do corte longitudinal de um perfil I simétrico e da posterior soldagem a outro perfil. Devido ao processo de obtenção, o perfil IFB se apresenta em duas configurações: IFB tipo A e IFB tipo B. O perfil IFB tipo A é obtido a partir do corte longitudinal de um perfil $\mathrm{H}$ ou I usualmente com altura de 500 ou $600 \mathrm{~mm}$ ao meio para que ao final o perfil assimétrico resultante tenha 250 ou $300 \mathrm{~mm}$ de altura; a partir do corte que resulta em um perfil de seção $\mathrm{T}$ uma chapa de aço com largura maior que a mesa superior é soldada formando a mesa inferior do perfil do perfil assimétrico (Figura 6b). De forma similar, o perfil IFB tipo B também resulta de um perfil $\mathrm{H}$ ou I cortado longitudinalmente ao meio, porém com a forma de uma seção $\mathrm{T}$ invertida à qual uma chapa de aço com largura inferior à da mesa inferior é soldada na parte superior da alma compondo o perfil assimétrico (Figura 6b). Assim como os demais perfis assimétricos, o perfil ASB também tem como principal característica geométrica a mesa inferior alargada, porém nesse caso, como se trata de um perfil laminado, a mesa inferior é 110 $\mathrm{mm}$ mais larga que a superior, resultado do próprio processo de fabricação do perfil, dispensando a necessidade de executar soldas para a composição do perfil (Figura 6c). O perfil ASB é comercializado com altura variando entre $272 \mathrm{~mm}$ e $342 \mathrm{~mm}$.

O perfil Deltabeam ${ }^{\circledR}$ é um perfil tubular formado por chapas de aço soldadas de maneira a formar um delta com altura (h) variando de $200 \mathrm{~mm}$ a $500 \mathrm{~mm}$ e largura da mesa inferior (B) variando de $395 \mathrm{~mm}$ a $860 \mathrm{~mm}$. Neste tipo de perfil são feitos orifícios com diâmetros de $80 \mathrm{~mm}$ ou 150 $\mathrm{mm}$ nas almas ao longo de todo o comprimento para permitir a passagem do concreto e das armaduras da laje (Figura 6d). A utilização do perfil Deltabem ${ }^{\circledR}$ em sistemas de piso misto de pequena altura é bastante interessante pois esse perfil permite que o comportamento conjunto aço-concreto seja conseguido por meio de um mecanismo que associa barras de aço e concreto, ambos passando através dos furos existentes nas almas do perfil de aço. Trata-se de um perfil com elevada rigidez a torção e isso facilita o processo de montagem do piso (NADASKY, 2012). Quando utilizados em pisos mistos de pequena altura podem ser combinados a lajes de vigotas treliçadas, lajes mistas e lajes pré-fabricadas de concreto. A utilização deste perfil patenteado está associada à possibilidade de vencer grandes vãos com perfis leves e que apresentam grande facilidade para embutimento de instalações para os mais variados serviços (elétrica, hidráulica, etc.). Podem ser obtidas áreas livres de 12 x 16m, com grande agilidade e facilidade no processo de montagem.

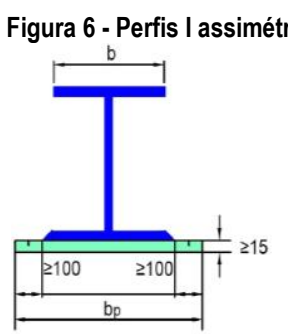

a)

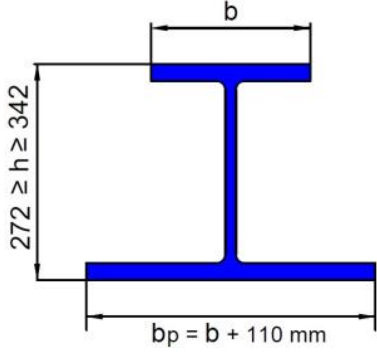

c)

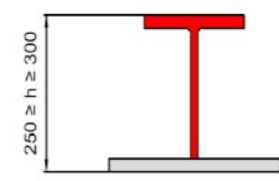

IFB - A

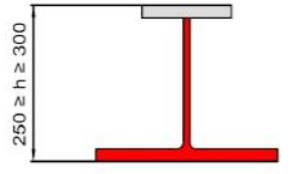

IFB - B b)

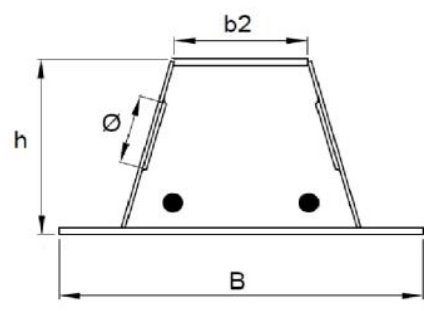

d)

Fonte:(a, b e c) Os autores; (d) Peikko Group (2014)

Quanto às lajes para os pisos mistos de pequena altura, essas podem ser do tipo maciça moldada in loco, mista com fôrma de aço incorporada, pré-fabricada ou prémoldada de concreto; dessas, destacam-se as lajes mistas com fôrma de aço incorporada e as pré-fabricadas, ambas por proporcionarem grande velocidade construtiva, dispensa de fôrmas e menor geração de resíduos de construção.

As lajes mistas com fôrma de aço incorporada consistem da associação de chapas de aço perfiladas e concreto moldado in loco; na fase final, após o endurecimento, o concreto atua estruturalmente em conjunto com a fôrma de aço, a qual funciona como toda ou parte importante da armadura positiva da laje (Figura 7a). Além disso, dependendo do vão, as lajes mistas podem dispensar escoramentos durante a fase de construção, as fôrmas funcionam como plataforma de trabalho para os operários, e dessa associação aço-concreto resultam lajes mais leves que as convencionais de concreto armado.

A utilização de lajes mistas como a mostrada na Figura 5a já é bastante grande no Brasil, normalmente associada a viga mista constituindo o piso misto convencional. Para utilização no piso misto de pequena altura o ideal é que a fôrma da laje mista seja mais alta, a fim de reduzir o volume maciço de concreto sobre a fôrma. No mercado estrangeiro são comercializadas fôrmas específicas para lajes mistas pertencentes ao piso misto de pequena altura com alturas de $210 \mathrm{~mm}, 220 \mathrm{~mm}$ e $225 \mathrm{~mm}$ e espessuras de 1,0 mm, 1,13 mm e 1,25 mm. Já no Brasil, ainda não há comercialização de uma fôrma especifica para o piso misto de pequena altura. 
A grande procura e utilização das lajes alveolares no sistema misto é devido à sua capacidade de ser combinada com qualquer sistema construtivo. Constituída de painéis de concreto (Figura 7b), geralmente protendidos, os alvéolos na seção transversal tornam esse tipo de laje mais eficiente que as lajes convencionais, isso porque há uma redução do peso do elemento sem perda considerável de resistência. Por ser um elemento industrializado, apresenta grande controle de qualidade tanto em termos de resistência quanto de geometria. A utilização de lajes préfabricadas alveolares contribui na velocidade de execução da obra, dispensa a utilização de escoramento durante a concretagem da capa, além de ser capaz de vencer grandes vãos e ter fácil instalação.

Figura 7 - Lajes utilizadas em sistemas de piso misto de pequena altura

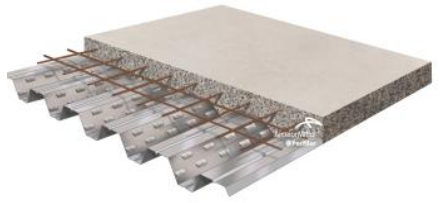

(a)

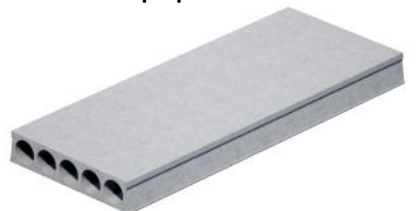

(b)
Fonte: (a) Perfilor (2017); (b) Prefabricar (2017)

\section{Processo construtivo}

De maneira bem simplista, o processo de execução do piso misto de pequena altura, independente do tipo de viga e de laje, se inicia com a montagem da estrutura metálica (vigas e pilares) para, em seguida, fazer a montagem e concretagem da laje ou de parte dela. A seguir são apresentadas as etapas e os procedimentos pertinentes a cada uma delas para se realizar uma correta execução, assim como os equipamentos necessários. Entretanto, cabe frisar que existem alguns cuidados a serem tomados com os materiais antes de iniciar o processo de execução da estrutura. Entre os cuidados pode-se destacar a verificação e controle de qualidade dos materiais no ato da entrega, o armazenamento em locais que atendam às especificações dos fabricantes e o correto manuseio tanto durante a execução como no transporte.

Outro fator de grande relevância, em qualquer etapa do processo construtivo, é a utilização dos equipamentos de proteção individual e coletiva. Desta forma, durante a execução devem ser utilizados todos os equipamentos de segurança individuais e coletivos exigidos pelas normas regulamentadoras em vigor.

A seguir são descritas as etapas usuais na execução das vigas, montagem e concretagem da laje.

\section{Execução das vigas mistas}

A primeira etapa para execução das vigas mistas é o içamento do perfil de aço. Por ser um elemento com elevado peso, a montagem dos perfis requer o auxílio de equipamentos de elevação como gruas ou guindastes.
Pinho (2005) salienta que é necessário conhecer o centro de gravidade da peça a ser içada para alocar os pontos de içamento de forma a não provocar instabilidades e deformações plásticas. Desta forma, é recomendado que se utilize dois pontos de içamento equidistantes em relação ao centro de gravidade (Figura 8). Esta recomendação deve-se à tendência de alinhamento entre o gancho do equipamento de elevação e o centro de gravidade da peça, em uma mesma prumada vertical.

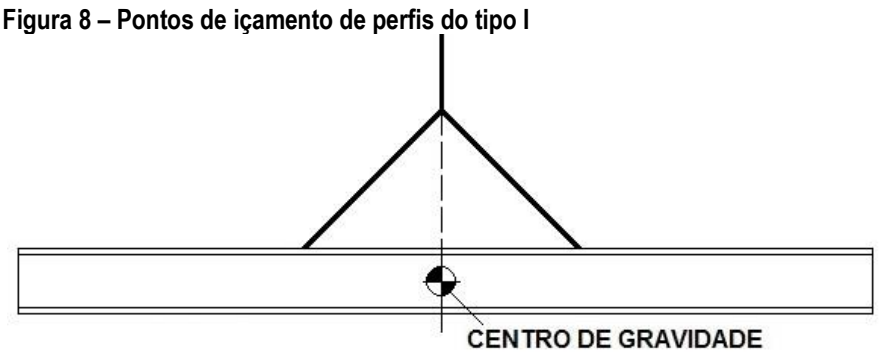

Fonte: Adaptado de Pinho (2005).

Os perfis Deltabeam ${ }^{\circledR}$ contam com furos dispostos na face superior projetados especialmente para a fixação das alças de içamento (Figura 9); esses furos facilitam todo o processo de elevação do elemento, enquanto que para os perfis I assimétricos, por não disporem de furos ou algo semelhante para realizar o içamento, é necessário fazer a amarração das vigas com cintas de içamento.

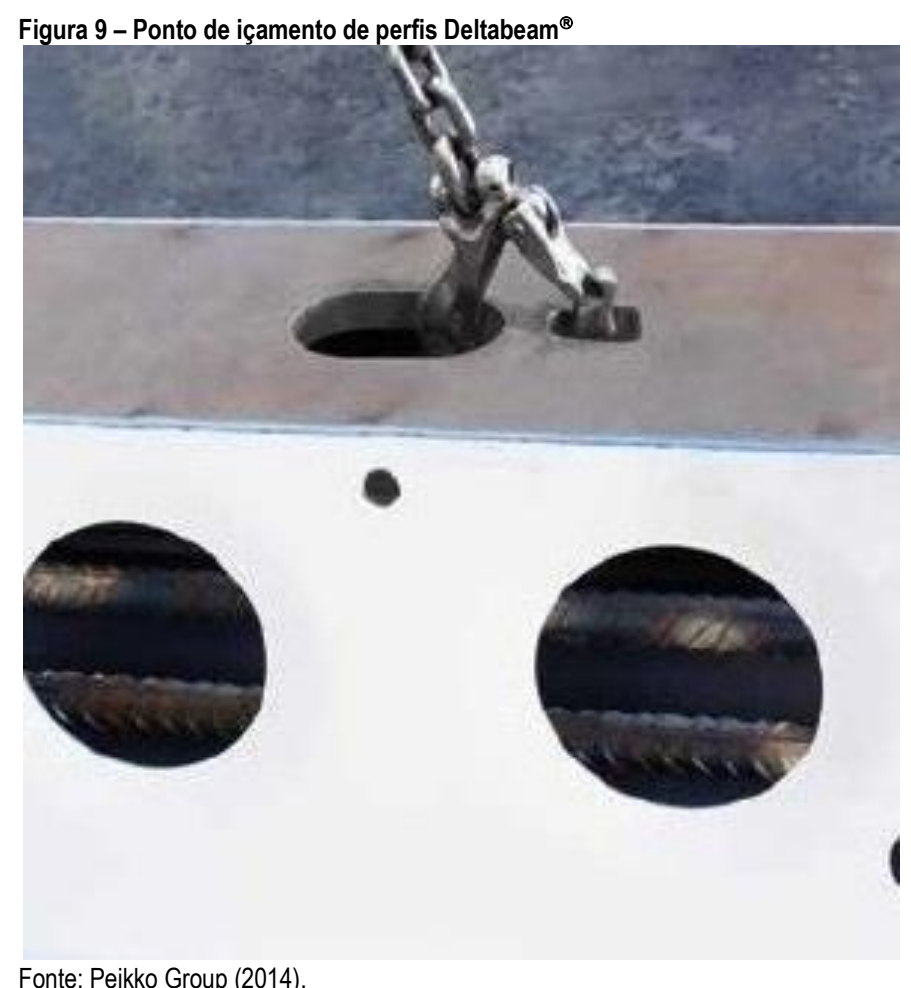

Fonte: Peikko Group (2014)

A execução de vigas inclinadas também é facilitada com a utilização dos perfis Deltabeam ${ }^{\circledR}$ (Figura 10). Essa facilidade confere maior produtividade e reduz o tempo de execução do sistema de piso. 
Após o içamento do perfil, são necessários o posicionamento e a fixação do perfil na estrutura. Com o devido posicionamento dos perfis das vigas mistas na estrutura, dá-se início ao processo de execução das ligações viga-pilar, que devem requerer poucas etapas in loco a fim de agilizar e facilitar essa etapa. Para os perfis I assimétricos as ligações podem ser soldadas ou parafusadas sendo que a escolha do tipo de ligação a utilizar fica a critério do engenheiro projetista. As ligações soldadas podem ser realizadas por um dos seguintes processos de soldagem: com eletrodo revestido, arco submerso, com proteção gasosa, arco com arame tubular ou proteção gasosa com eletrodo de tungstênio. No caso da ligação soldada é necessária a remoção de qualquer tipo de resíduo na superfície dos elementos a serem soldados e o metal utilizado no eletrodo dever ser compatível com o metal-base do elemento. Para a soldagem é necessário máquina de solda compatível com o processo de soldagem escolhido e uma fonte de energia elétrica. Ao final do processo é recomendado que haja uma inspeção para verificar a qualidade das soldas realizadas e se as mesmas estão de acordo com a ABNT NBR 8800:2008.

Figura 10 - Encontro de vários perfis Deltabeam ${ }^{\circledR}$

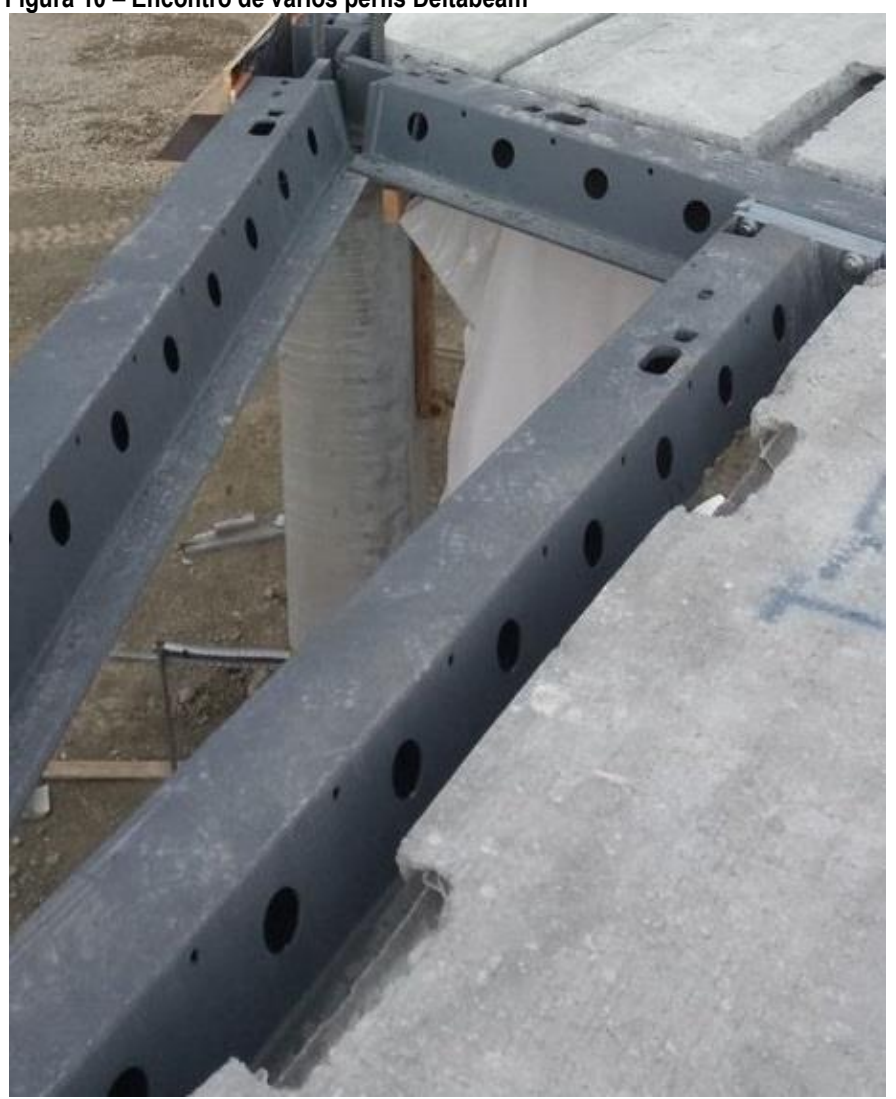

Fonte: Peikko Group (2017).

Nas ligações parafusadas o ideal é que os furos nos perfis dos pilares e vigas sejam feitos na fábrica a fim de evitar esse tipo de trabalho no canteiro de obra. Assim como no processo de soldagem, no caso da ligação parafusada as superfícies dos elementos devem estar livres de qualquer tipo de resíduo ou imperfeição que obstrua a ligação entre elementos. Com as superfícies verificadas, o perfil é içado e posicionado de maneira que os furos da viga se alinhem com os do pilar para então iniciar o processo de conexão entre os elementos. Deve-se garantir que todos os parafusos sejam apertados e que o torque aplicado não exceda aos limites de capacidade resistente dos parafusos; esse tipo de falha pode ser evitado utilizando parafusos com indicador de aperto.

A ligação viga-pilar para os perfis Deltabeam ${ }^{\circledR}$ é feita por meio de um consolo de aço. Uma placa de fixação é integrada ao interior do pilar antes da concretagem, após a concretagem o consolo é parafusado na placa de fixação (Figura 11a) e o perfil Deltabeam ${ }^{\circledR}$ é apoiado sobre o consolo (Figura 11b). Dependendo do detalhe de ligação, pode haver ou não continuidade na ligação (transferência de momento fletor).

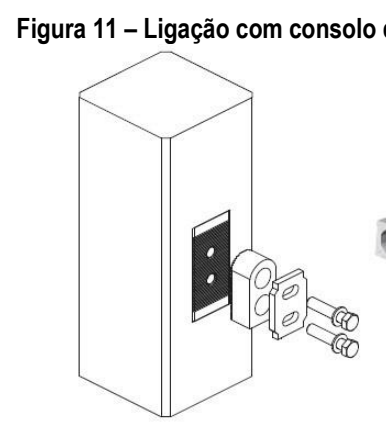

(a)

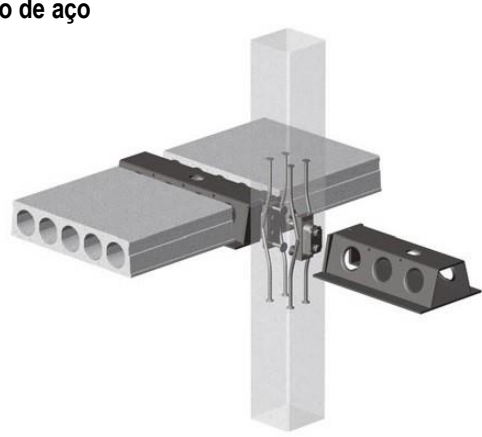

(b)
Fonte: Adaptado de Peikko Group (2016)

Uma vez executadas as ligações entre os componentes de aço, a próxima etapa é o escoramento dos perfis; essa etapa pode ser dispensada caso os perfis das vigas tenham sido verificados considerando construção não escorada. Caso contrário, é necessário realizar o escoramento das vigas até que o comportamento conjunto aço-concreto seja atingido.

Nos perfis I a presença de escoramento interfere diretamente no processo de dimensionamento das vigas mistas, ficando a critério do responsável pelo projeto estrutural especificar a necessidade ou não do escoramento. No caso dos perfis Deltabeam ${ }^{\circledR}$, como a viga é simplesmente apoiada sobre o consolo, na fase construtiva existe a necessidade de escoras junto às ligações viga-pilar periféricas a fim evitar a rotação do perfil em torno do eixo longitudinal, proveniente do desequilíbrio de carga causado pela laje apoiada apenas em um lado da viga. Após o endurecimento, o concreto faz o papel de contenção do perfil Deltabeam ${ }^{\circledR}$. Uma vez que toda a estrutura metálica já está posicionada e devidamente conectada, a próxima etapa é a execução da parte em concreto. 


\section{Execução das lajes}

Após a montagem da estrutura metálica (perfis de vigas e pilares) é dado início ao processo de execução da laje; essa etapa dependerá do tipo de laje previamente selecionado. Em função das especificidades de cada tipo de laje, este item foi dividido em: laje mista com fôrma de aço incorporada e laje alveolar em concreto.

\section{Lajes mista com fôrma de aço incorporada}

A montagem da laje mista se inicia com o posicionamento e fixação dos diafragmas finais na mesa inferior dos perfis de aço (Figura 12). Isto deve ser feito em ambos os lados do perfil que a laje se apoia, exceto para os perfis de borda.

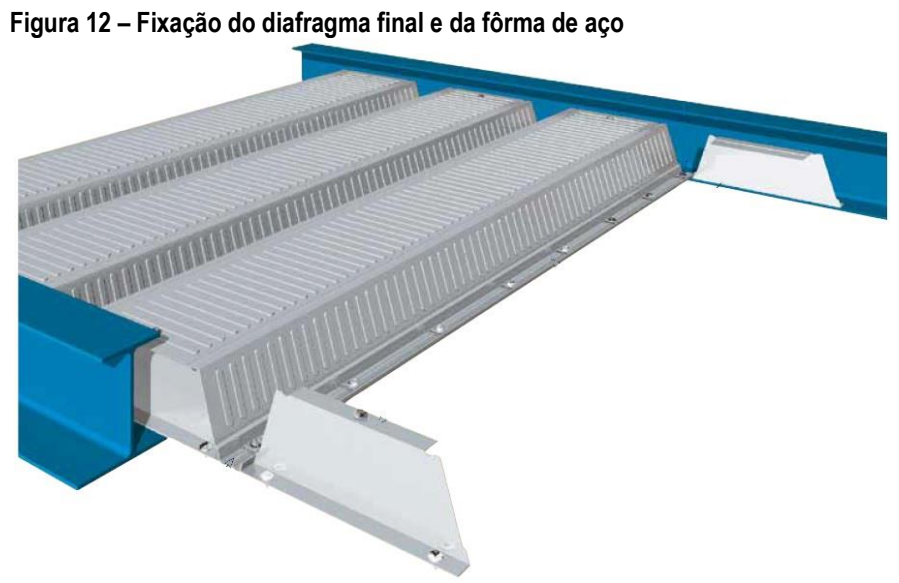

Fonte: Adaptado de Tata Steel (2016).

Após a fixação dos diafragmas finais é iniciado o içamento das fôrmas, com o auxílio de guindastes ou gruas, até uma posição que permita que operários realizem sua a montagem e fixação nos perfis das vigas; essa fixação normalmente também é feita com parafusos. Para ambos os tipos de perfis (I assimétrico e Deltabeam ${ }^{\circledR}$ ) as fôrmas de aço são fixadas na mesa inferior dos perfis de modo que as fôrmas de aço que se apoiam paralelamente ao perfil de aço devem ter no mínimo $50 \mathrm{~mm}$ de comprimento de apoio (Figura 13a) e caso as fôrmas se apoiem ortogonalmente ao perfil o comprimento de apoio deve ser de no mínimo $20 \mathrm{~mm}$ (Figura 13b).

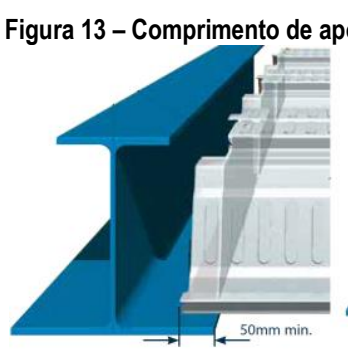

(a)

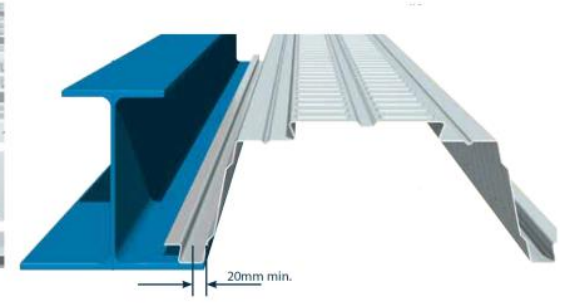

(b)
Fonte: Adaptado de Tata Steel (2016).

Nos casos em que a laje mista apoia-se em paredes em alvenaria é necessário que a parede tenha no mínimo 100 mm de largura e o comprimento de apoio devem ser de no mínimo 75 mm (Figura 14).

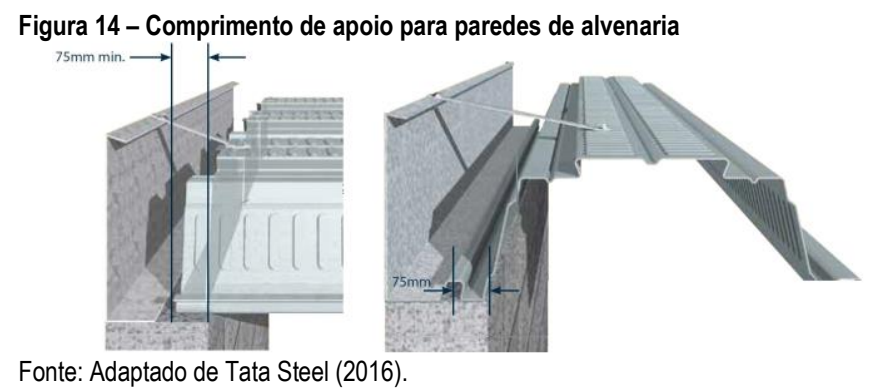

Nos perfis I assimétricos o comportamento conjunto entre os materiais aço e concreto é garantido pelos conectores de cisalhamento soldados na viga; existe a possibilidade de fixar os conectores na mesa superior ou inferior do perfil de aço da viga (DE NARDIN; EL DEBS, 2009). A etapa de fixação dos conectores deve ser realizada em fábrica, antes da montagem e fixação do perfil da viga mista. A fixação de conectores em canteiro reduz a produtividade e o tempo de montagem da estrutura de aço. Já nos perfis Deltabeam ${ }^{\circledR}$ não é necessária a utilização de conectores de cisalhamento pois o comportamento conjunto se dá pela passagem do concreto e de armaduras através dos furos na alma do perfil (ver Figura 19a).

A necessidade de escoramento das lajes mistas depende da capacidade resistente à flexão da fôrma de aço utilizada e do vão da laje; a condição ideal é que todo escoramento seja dispensado. Os fabricantes fornecem, para cada modelo de fôrma, as especificações quanto à necessidade e de como deve ser executado o escoramento.

A laje mista pode dispensar totalmente a utilização de barras de aço como armadura positiva da laje; caso necessário, essa armadura pode ser complementada por barras dispostas em cada nervura da fôrma (Figura 15a), sendo necessária a utilização de espaçadores para o correto posicionamento das barras nas nervuras. A fim de combater a fissuração por retração, distribuir os efeitos de cargas pontuais e contribuir para a capacidade resistente à flexão em situação de incêndio uma malha de aço deve ser colocada próximo ao topo da laje (Figura 15b), respeitando os cobrimentos recomendados pela NBR 6118 (ABNT, 2014). Além das armaduras citadas, caso a laje mista tenha continuidade, as armaduras negativas devem ser dispostas junto aos apoios intermediários de forma a garantir a continuidade e resistir aos momentos negativos.

Após o correto posicionamento das armaduras, a próxima etapa é a concretagem em si. Antes de iniciar o processo de concretagem é recomendado que se faça uma vistoria para remoção de qualquer tipo de resíduo que possa estar depositado sobre as fôrmas de aço. A depender do pavimento a executar a concretagem, pode ser necessária a utilização de uma bomba (estacionária ou lança) para 
efetuar o lançamento do concreto até a posição correta. A bomba-lança faz o transporte do concreto direto do caminhão betoneira até o local desejado através de uma lança, já na bomba estacionária o concreto é despejado do caminhão betoneira na bomba que leva o concreto através de tubulações até o local desejado. Ou seja, a utilização do segundo tipo de bomba pode resultar em maior tempo de execução.

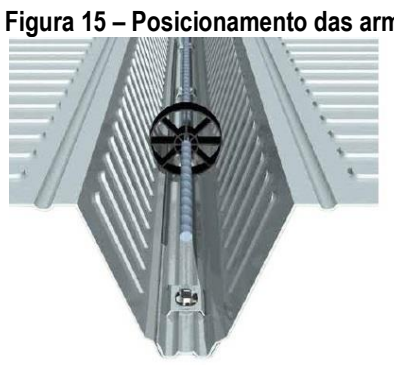

(a)

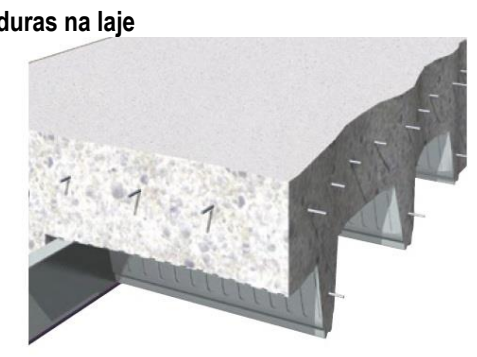

(b)
Fonte: Adaptado de Tata Steel (2016).

Durante o lançamento do concreto é necessário que o operário responsável pela mangueira de lançamento espalhe de maneira uniforme para evitar a possibilidade de acúmulos pontuais concreto em estado fresco. Esse efeito de empoçamento, caso seja significativo, deve ser considerado utilizando o procedimento descrito no item Q.4.1.4 da ABNT NBR 8800 (2008). Uma vez concluída a concretagem deve ser respeitado o tempo de cura e executados todos os procedimentos necessários à correta cura do concreto a fim de garantir a resistência mínima.

Quando necessário realizar aberturas na laje mista deve-se atentar-se para as limitações e recomendações quanto as dimensões e a necessidade de reforços. Para realizar a abertura pode-se utilizar fôrmas (Figura 16a) ou fixar um bloco de poliestireno (Figura 16b) na posição desejada. Só após o concreto da laje atingir $75 \%$ da sua resistência de projeto a fôrma de aço pode então ser cortada.

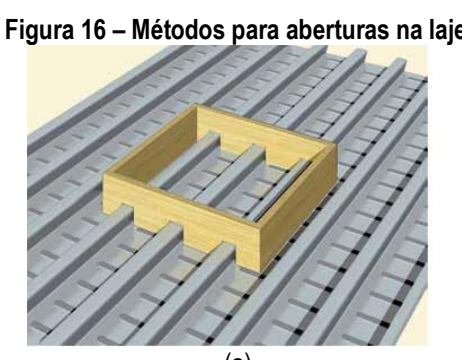

(a)

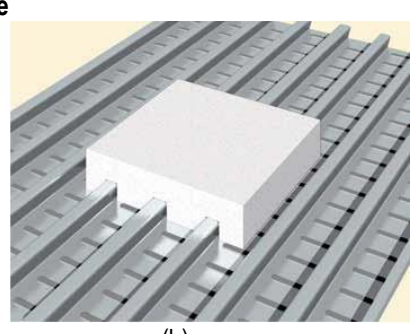

(b)
Fonte: Tata Steel (2016)

Segundo recomendado por manuais técnicos, em aberturas de até $300 \mathrm{~mm}$ x $300 \mathrm{~mm}$ não é necessário reforços adicionais. Para aberturas de até $400 \mathrm{~mm}$ de largura e 1000 $\mathrm{mm}$ de comprimento o reforço necessário deve ser dimensionado de acordo com a norma em vigor e dispostos em torno da abertura. Aberturas de até $1000 \mathrm{~mm}$ de largura e $2000 \mathrm{~mm}$ de comprimento podem ser acomodadas removendo uma chapa da fôrma de aço e fixando fôrmas de borda, o reforço adicional deve ser disposto em torno da abertura. Caso a abertura seja superior a $300 \mathrm{~mm}$ x $300 \mathrm{~mm}$ e estiver dentro da largura efetiva da laje, a viga de apoio não deve ser projetada como mista (TATA STEEL, 2016).

\section{Laje alveolar}

O processo de içamento das placas que formam as lajes alveolares é semelhante ao das vigas, já apresentado no item 3.1. Entretanto, fabricantes de lajes alveolares aconselham que a cinta de içamento seja posicionada de modo que o balanço nas extremidades das lajes seja de no máximo de $30 \mathrm{~cm}$. A NBR 9062 (ABNT, 2017) em seu item 5.3.3.2 recomenda que o ângulo entre a cinta de içamento e a laje seja de no mínimo $45^{\circ}$ (Figura 17).

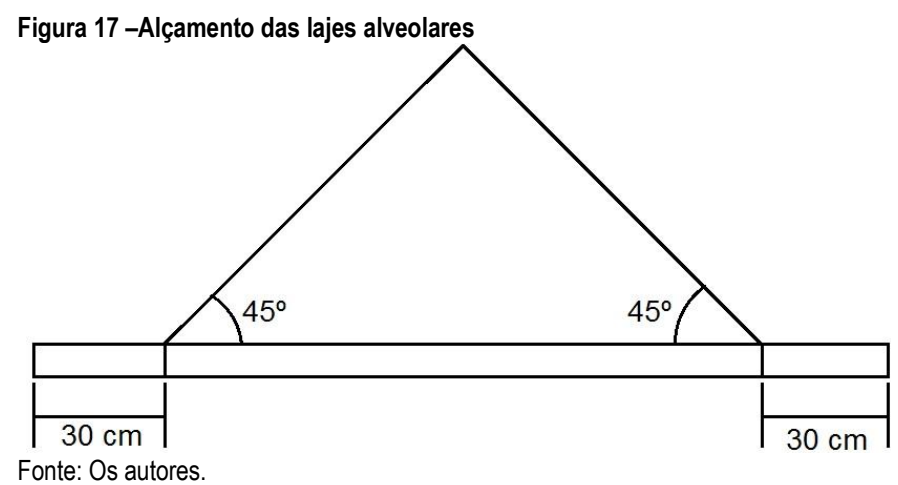

Nos perfis Deltabeam ${ }^{\circledR}$, conforme recomendação do fabricante e detentor da patente, as lajes devem ser posicionadas de modo que haja uma folga de no máximo $30 \mathrm{~mm}$ entre a face externa da laje e a alma do perfil (Figura 18a). No caso dos perfis ASB com distância entre vigas entre 1,5 e $11 \mathrm{~m}$, recomenda-se que o comprimento de apoio deve ser de $80 \mathrm{~mm}$ e, quando necessário, deve ser realizado um chanfro para facilitar a instalação das placas da laje (RACKHAM; HICKS; NEWMAN, 2006) como mostrado na Figura 18b.

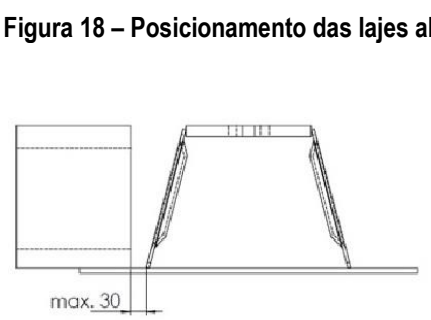

(a)

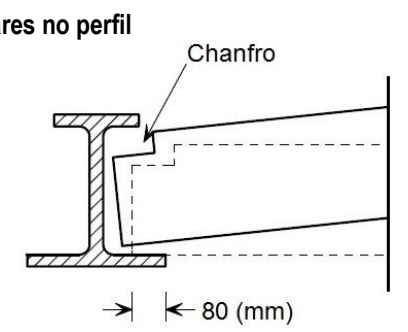

(b)
Fonte: (a) Peikko Group (2014); (b) Adaptado de Rackham, Hicks e Newman (2006).

Quanto ao escoramento, as lajes alveolares dispensam o uso de escoramentos, o que acelera o processo de execução e se constitui numa característica extremamente positiva deste tipo de laje. 
Com as lajes posicionadas é dado início à colocação das armaduras; nessa etapa pode ser necessário realizar a abertura de alvéolos para posicionar a armadura longitudinal durante o processo de montagem da laje. Nos perfis Deltabeam ${ }^{\circledR}$ as barras de aço são colocadas através dos orifícios na alma do perfil (Figura 19a).

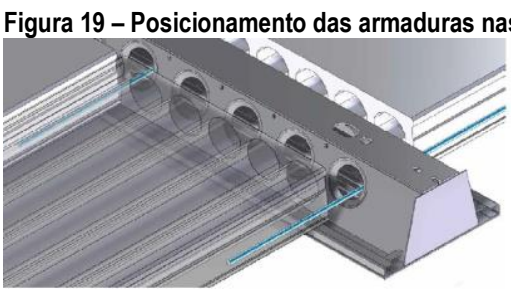

(a)

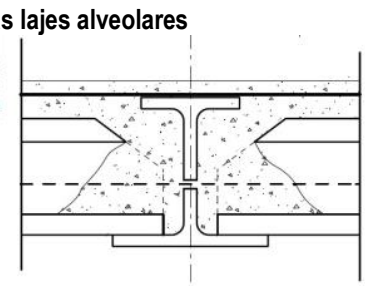

(b)
Fonte: (a) Peikko Group (2014); (b)Adaptado de Rackham, Hicks e Newman (2006).

No caso dos perfis I assimétricos as barras podem ser colocadas de duas maneiras: através de furos feitos na alma do perfil ou sobre a mesa superior juntamente com a malha de aço (Figura 19b). Deve ser executada abertura de no máximo dois alvéolos por unidade de placa alveolar a fim de evitar reduções de resistência por conta da quantidade de aberturas (RACKHAM; HICKS; NEWMAN, 2006).

Posicionadas as armaduras, as lajes alveolares requerem primeiro o grauteamento e, posteriormente, a concretagem da capa de concreto, quando esta se fizer necessária. $\mathrm{O}$ processo de grauteamento é similar para ambos os tipos de perfis, no entanto nos perfis Deltabeam ${ }^{\circledR}$ o grauteamento deve ser iniciado pelo preenchimento dos orifícios na parte superior do perfil. O fabricante do perfil Deltabeam ${ }^{\circledR}$ recomenda que o preenchimento do perfil deve ser iniciado pelo centro do perfil, com o auxílio de um mangote para realizar o correto adensamento e eliminar vazios de concretagem. O nível de preenchimento do perfil pode ser acompanhado e verificado através dos furos na alma (Figura 20). Também se sugere que, no caso do perfil Deltabeam ${ }^{\circledR}$ ser associado a um pilar misto de aço e concreto, esse último seja preenchido primeiro, depois o perfil Deltabeam ${ }^{\circledR}$ e por fim as chaves de cisalhamento da laje. A fim de garantir a estabilidade da edificação, a execução do grauteamento deve ser feita imediatamente após a montagem dos elementos pré-fabricados a fim de solidarizar todos eles e compor um piso resistente às ações horizontais. Caso isso não seja feito, deve ser previsto algum tipo de estabilização lateral provisória da edificação.

O tempo de cura do graute deve ser respeitado; uma vez concluída a cura, dá-se início à colocação da malha de aço, normalmente em tela soldada, sobre a laje alveolar e executa-se a concretagem de uma capa de concreto em todo o piso. Esse processo de concretagem é idêntico ao da laje mista. Após a concretagem deve ser realizada a cura da capa de concreto.

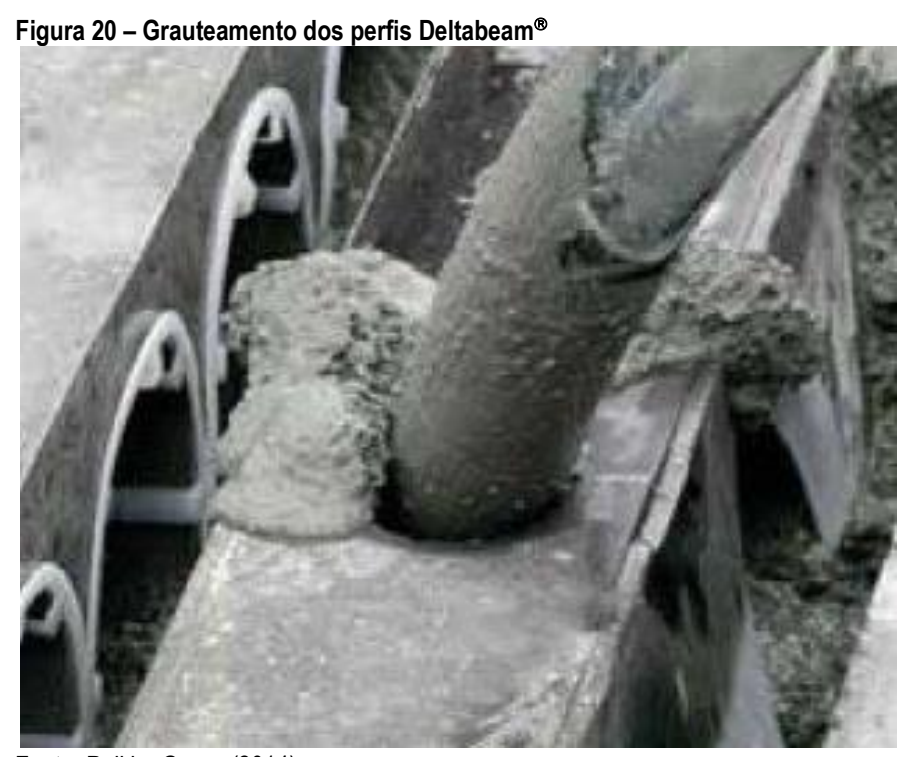

Fonte: Peikko Group (2014).

\section{Considerações finais}

Com a crescente utilização das estruturas mistas de aço e concreto no Brasil torna-se necessário ampliar os estudos envolvendo os procedimentos de execução de tal sistema construtivo. Como descrito ao longo desse trabalho, os equipamentos e mão de obra necessários à execução de pisos mistos de pequena altura são idênticos aos utilizados em sistemas de aço ou de concreto pré-fabricado. No tocante à mão de obra, assim como em outros sistemas, é preciso que esta seja adequadamente treinada a fim de evitar retrabalhos e a geração de grandes volumes de resíduos de construção. Vale destacar que de nada adianta optar por um sistema com alto grau de industrialização se o processo de execução continuar utilizando procedimentos arcaicos e onerosos. Na composição de custo de um produto ou serviço a mão de obra é uma das variáveis que mais reflete no valor final. Isto não se dá somente por conta de salários, impostos etc., pois, mal qualificada, pode tornar o serviço mais lento, causar retrabalhos aumentando a geração de resíduos e consumo de material e a possibilidade de acidentes.

Como mostrado no presente trabalho, o processo construtivo do piso misto não requer serviços que necessitem de técnicas e equipamentos específicos. Visto que atualmente existe uma carência em materiais voltados para o processo de execução do sistema misto, espera-se contribuir para a difusão do sistema construtivo e proporcionar uma melhor compreensão das técnicas inerentes ao processo de construção das tipologias aqui abordadas. 


\section{Referências}

ABNT - ASSOCIAÇÃO BRASILEIRA DE NORMAS TÉCNICAS. NBR-6118: Projeto de estruturas de concreto Procedimentos. Rio de Janeiro, 2014.

ABNT - ASSOCIAÇÃO BRASILEIRA DE NORMAS TÉCNICAS. NBR-8800: Projeto de estruturas de aço e de estruturas mistas de aço e concreto de edifícios. Rio de Janeiro, 2008.

ABNT - ASSOCIAÇÃO BRASILEIRA DE NORMAS TÉCNICAS. NBR-9062: Projeto e execução de estruturas de concreto prémoldado. Rio de Janeiro, 2017.

ARCELORMITTAL. Slim floor an innovative concept for floors. Luxemburgo, 2014.

BAILEY, C.G. The behaviour of asymmetric slim floor steel beams in fire. Journal of Constructional Steel Research, v. 50, p. 235-257, 1999.

FEDERATION INTERnAtional DU BETON FIB. Precast Concrete in Mixed Construction, Lausanne, n. $19,2002$.

JURADO, M. G. Estudio del comportamiento estructural de los forjados tipo “slim floor” bajo cargas de servicio. 2008. 154p. Tesis (Doctorado) - Universitat Politècnica de Catalunya, Barcelona, 2008.

MA, Z.; MAKELAINEN, P. Behavior of composite slim floor structures in fire. Journal of Structural Engineering, v. 126, p. 830-837, 2000.

NÁDASKÝ, P. Steel-Concrete Composite Beams for Slim Floors - Specific Design Features in Scope of Steel Frames Design. Procedia Engineering, v. 40, p. 274-279, 2012.

PEIKKO GROUP. Deltabeam composite beam. Lahti, 2014.

PEIKKO GROUP. Corbel system to support beams. Lahti, 2016.

PEIKKO GROUP. Disponível em: < http://references.peikko.com/reference/luxenbourg-ii-iii/? ga=2.42753635.731790971.1503409754-198971134.1491333972 >. Acesso em: ago. 2017.

PEIKKO GROUP. Disponível em: http://peikkousa.blogspot.com.br/2016/08/deltabeam-faq.html . Acesso em: set. 2017.

PERFILOR. Telha forma colaborante polydeck 59s. Disponível em:

http://www.perfilor.com.br/lermais materias.php?cd materias=142. Acesso em: mai. 2017.

PINHO, M.O. Transporte e montagem. Rio de Janeiro: IBS/CBCA, 2005.

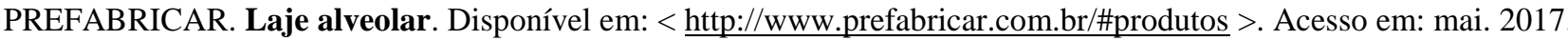

QUEIROZ, Gilson, PIMENTA, R. J., CALIXTO, J. M., MATA, Luciene A. C. A new type of slim floor. Journal of Constructional Steel Research, v. 46, p. 1-12, 1998.

DE NARDIN, S.; EL DEBS, A.L.H.C. Study of partially encased composite beams with innovative position of stud bolts. Journal of Constructional Steel Research, v. 65, p. 342-350, 2009.

RACKHAM, J. W; HICKS, S. J; NEWMAN, G. M. Design of asymmetric slimflor beams with precast concrete slabs. UK: The Steel Construction Institute, 2006.

SOMMER, R. M. R. Análise de vibrações em pisos mistos aço/concreto. 2002. 140p. Dissertação (Mestrado) - Universidade Federal de Minas Gerais, Belo Horizonte., 2002.

TATA STEEL. Composite floor decking design and technical information. Londres, 2016.

TATA STEEL. Disponível em: < https://www.tatasteelconstruction.com/en_GB/tata-steel-case-studies/other/Chasse-Church >. Acesso em: ago. 2017. 


\section{${ }^{1}$ Raimundo Fagner de Freitas Kochem}

Engenheiro Civil. Mestre em Estruturas e Construção Civil. Endereço postal: Rod. Washington Luís, km 235, SP-310, São Carlos, Brasil, 13565-905.

\section{Silvana De Nardin}

Engenheira Civil. Doutora em Estruturas. Professora Adjunta na Universidade Federal de São Carlos. Endereço postal: Rod. Washington Luís, km 235, SP-310, São Carlos, Brasil, 13565-905. 